\title{
Calculation of humidity of autoclave cellular composites under service conditions
}

\author{
GAGARIN Vladimir Gennadievich ${ }^{1, a}$, PASTUSHKOV Pavel Pavlovich ${ }^{2, b}$, \\ PAVLENKO Natalia Victorovna ${ }^{3, c}$, FOMINA Ekaterina Victorovna ${ }^{4, d}$, \\ RUBANOV Yuriy Konstantinovich ${ }^{5, \mathrm{e}}$ \\ ${ }^{1}$ Moscow State University of Civil Engineering, Russia \\ ${ }^{2}$ Research institute of construction physic of RAACS, Russia \\ ${ }^{3}$ Moscow State University, Russia \\ ${ }^{4,5}$ Belgorod State Technological University named after V.G. Shoukhov, Russia

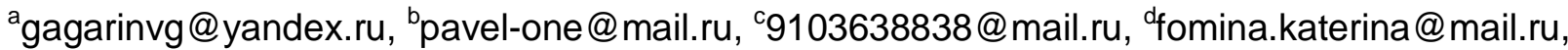 \\ eyrubanov@yandex.ru
}

Key words: humidity regime, unsteady calculation method, autoclave cellular composite, full-scale studies, service humidity, sorption, water vapor transmission

Abstract. Analysis of design methods of humidity regime for multilayered wall structures based on cellular autoclave composites is realized. Relevance of arrange of study of cellular composite work humidity is proved. Experimental studies were curried up as well as results of sorption wetting and water vapor transmission for basic grades of cellular composite were accomplished. The results of calculation of humidity regime for wall construction based on gas concrete (grades of gas concrete - D400) with front heat-insulating composite system and external plaster layers for different climatic zone for construction as well as service humidity for material in studied wall structures.

\section{Introduction}

During maintenance of buildings, humidity of materials in building envelope is varied in dependence with design feature, material properties, temperature and humidity conditions in accommodation, and climatic conditions in construction zone [1-6]. Humidity regime determines experience of building envelopes of building, that directly influent on thermal characteristics of building envelopes [7-9] as well as on energy efficiency of applied construction materials [10].

Calculation of humidity regime allow solution of different tasks in construction thermophysics. Steady method of Humidity regime estimation according to [11] allows inspecting a construction for conditions of infeasibility of moisture collection during one year working period as well as limits in humidity during period of below zero monthly mean outside air temperature. Calculation with unsteady methods [12-14] allows qualitative humidity estimation in building envelopes and required quantitative results concerning humidity content in layers of construction materials. The main results of humidity regime calculation for wall structure with using of unsteady methods are moisture distribution through depth of construction of building at any time of service period. These data can provide with solution for some questions, for example, determination of service humidity of construction materials. From these results the such problem as estimation of opportunity of environment creation for generation of bacteria, initiated microbiologic destruction of construction materials can be realized.

Prospective of this study: autoclave cellular composites at present time is the most widely used material, applied in enclosing parts of building [15]. The last studies for problem of humidity regime curried out for cellular composites with other heat and humidity characteristics (because of the equipment stock for production process was replaced; technologies and compositions were updated; D300 and D400 grades of concrete become more actual due to stepping up the requirements to thermal protection).

Service humidity is balanced moisture content of material in envelope construction relatively affected moisture internal and external medium. Moisture content in construction become balanced 
after some years of building service [14]. Translation period of humidity regime of construction to quasi steady one depends on initial (technological) material humidity, construction structure and climatic conditions of construction area. Results of calculation and full-scale studies demonstrates the translation period for construction containing gas concrete is $1-5$ years [5, 14,16-19].

The base method of determination of service moisture is full-scale study, as it allows determination of moisture contribution for certain construction in certain service conditions. However, results of full-scale studies could varied significantly even for identical constructions in equal service conditions [20]. On the base of large number of full-scale studies, as well as according to expert analysis the values of calculated moisture in service conditions A and B (in accordance with appendix C) were chosen [11]. This values are varied slightly in regulatory document " Buildings Heat Insulation " of different issues. But for some construction materials such as gas concrete with moisture value of 8 and $12 \%$ in service conditions $\mathrm{A}$ and $\mathrm{B}$, respectively, for these parameters are outdated (items 176-179, appendix C) [11]

At present time all full-scale studies, that could be as basic calculated thermo-technical parameters in regulatory documents is not possible to realize because of its expensiveness as well as the state financing of research activity in construction field is absent. Also regular relationship between construction enterprises and sectoral research centers, affected since the Soviet period are weak. Therefore application of digital calculation method for moisture regime of building envelope is more prospective now [8,12-14].

Unsteady calculation methods of humidity regime are known since 1930s. In 1984 in the Research Center of Building Physics the "Manual on calculation of humidity regime for building envelope" [21] was developed. It is the most complete manual for unsteady calculations. Actualization of this method was realized and new standard: GOST 32494-2013. Regional standard" Buildings and structures. Method of mathematic modeling of temperature-humidity regime in building envelopes" was issued in the last 2 years.

\section{Experimental part}

For realization of temperature-humidity characteristics for autoclave cellular composite the some experimental studies for autoclave gas concrete samples with grades D300, 400, 500, 600were accomplished. The most significant obtained results are values of moisture vapor transmission and sorption of water steam. It because of for the first time in recent years the basic grades of autoclave gas concrete of present-day production were tested according to standard methods with special equipment. Also for the first time the methods were tested and results of capillary rise and hydraulic conductivity were obtained for present-day production gas concrete.

Average data of experimental studies on sorption of water steam for samples of basic grades of autoclave gas concrete are shown in Table 1. The research was curried out according to GOST 24816-81 (Russian Standard). Sorption isotherms are shown in Fig.1

Table 1 Data of sorption for autoclave cellular composite samples

\begin{tabular}{|c|c|c|c|c|c|}
\hline \multirow{2}{*}{$\begin{array}{c}\text { Grade of gas } \\
\text { concrete }\end{array}$} & \multicolumn{5}{|c|}{ Moisture content, \%, by wt., } \\
\cline { 2 - 6 } & 40 & 60 & 80 & 90 & 97 \\
\hline D300 & 0,102 & 0,36 & 1,9 & 3,15 & 6,3 \\
\hline D400 & 0,063 & 0,22 & 1,32 & 2,48 & 4,54 \\
\hline D500 & 0,036 & 0,16 & 1,23 & 2,19 & 4,25 \\
\hline D600 & 0,021 & 0,083 & 1,1 & 2,08 & 4,00 \\
\hline
\end{tabular}




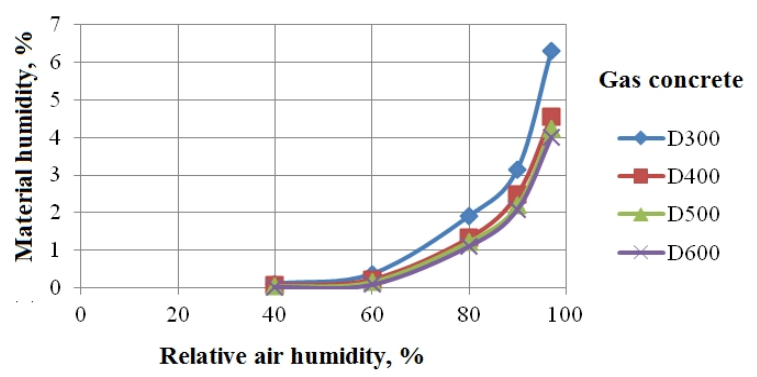

Fig. 1 Sorption isotherms of autoclave cellular composites

The data obtained allows concluding following: the gas concrete density is less the sorption is better. It can be associated with better porosity of cellular composite when density reducing.

Average data of water vapor permeability resistance as well as calculated vapor permeability coefficients for basic grades of gas concrete are demonstrated in Table 2. Studies were accomplished according to GOST 25898-2012. Thickness of the studied samples is $25 \mathrm{~mm}$.

Table 2 Data of vapor permeability for gas concrete

\begin{tabular}{|c|c|c|c|}
\hline Grade of gas concrete & $\begin{array}{c}\text { Medium density of } \\
\text { samples, } \rho, \mathrm{kg} / \mathrm{m}^{3}\end{array}$ & $\begin{array}{c}\text { Water vapor permeability } \\
\text { resistance, } R_{\Pi}, \mathrm{m}^{2} \cdot \mathrm{h} \cdot \mathrm{Pa} / \mathrm{mg}\end{array}$ & $\begin{array}{c}\text { Vapor permeability, } \\
\mu, \mathrm{mg} /(\mathrm{m} \cdot \mathrm{h} \cdot \mathrm{Pa})\end{array}$ \\
\hline D300 & 330 & 0,198 & 0,126 \\
\hline D400 & 410 & 0,215 & 0,120 \\
\hline D500 & 504 & 0,240 & 0,105 \\
\hline D600 & 634 & 0,268 & 0,095 \\
\hline
\end{tabular}

According to these data we can say the higher gas concrete density the higher water vapor permeability resistance, the less vapor permeability coefficient.

\section{Calculation}

On the basis of thermal and humidity characteristics of cellular composites the trial calculation of unsteady humidity regime of multilayer wall structures in climate conditions of different cities were accomplished. Walls from gas concrete (D400) with facade system and bonded heat insulation using of basic types of insulators such as fiberglass, formed and extruded cellular polystyrene with surface thin plaster layer were studied. When calculation was accepted the temperature and humidity in room are $+20{ }^{\circ} \mathrm{C}$ and $55 \%$, respectively and are constant during a year. Temperature and relative air humidity outside of construction is varied. For calculation data from the Construction Regulations СП 131.13330.2012. Updated issue of the Construction Standards and Regulations 23-01-99* «Cconstruction climatology» were used.

Fig. 2-4 demonstrates curves of humidity contribution over the thickness of construction in different cities, obtained as result of calculation on the base of developed computer program, according to [21], realizing mathematical model of temperature-humidity regime for envelope construction from GOST 32494-2013.

Results of study are presented for third year of building service. It is connected with during two years all studied versions of construction loose initial (technological) humidity and achieve quasistationary humidity regime. For each construction there are two diagrams: humidity distribution for starts of months, followed in months with maximum and minimum moisture accumulation in construction (in start of February and August respectively).

On the basis of calculated data of humidity regime for studied version of construction the values of service moisture content in materials for climate conditions of choosed cities were defined. Results of service moisture content for gas concrete (D400) as well as effective insulators after a month of maximum moisture accumulation are shown in Table 3. Parameters for gas concrete are presented for construction containing extruded polystyrene foam 


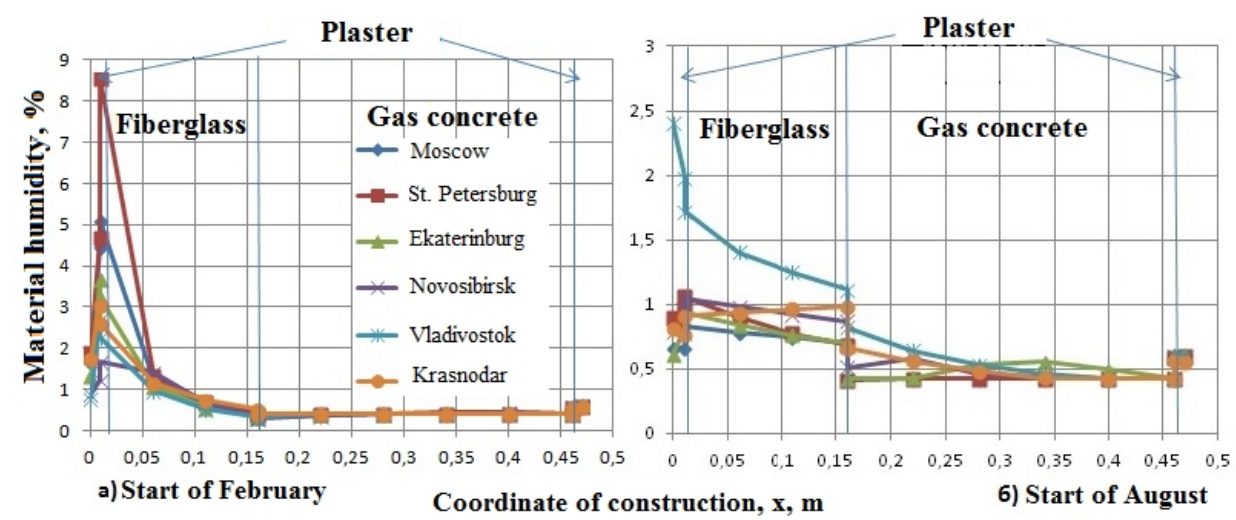

Fig. 2. Humidity contribution inside of construction containing fiberglass

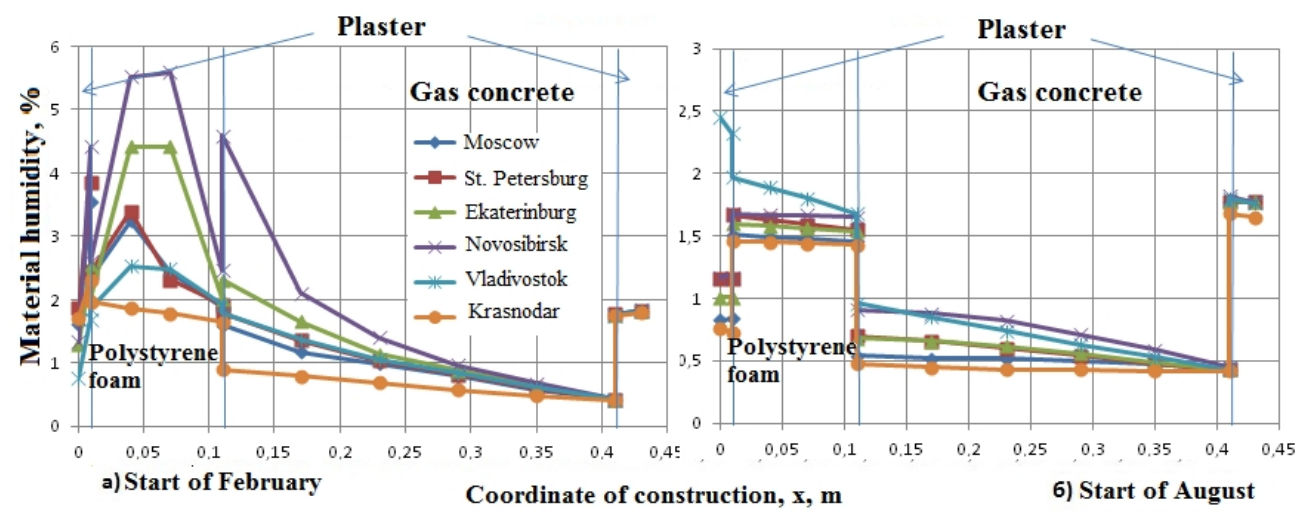

Fig. 3. Humidity contribution inside of construction containing polystyrene foam

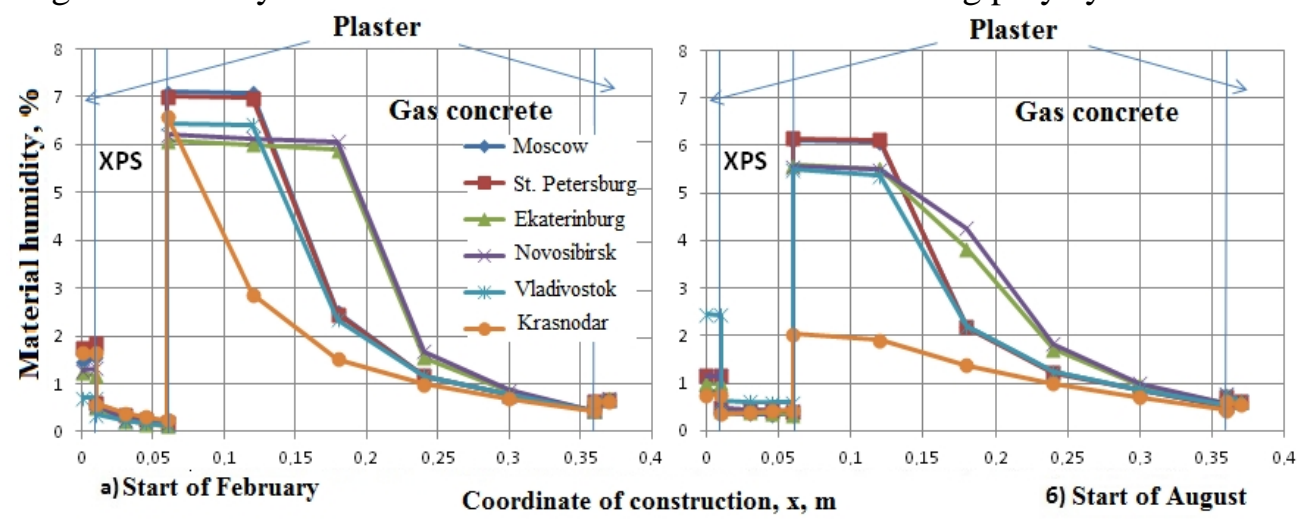

Fig. 4. Humidity contribution inside of construction containing extruded polystyrene foam

Table 3

Service moisture content after a month of maximum moisture accumulation

\begin{tabular}{|l|c|c|c|c|c|c|}
\hline \multirow{2}{*}{ Material } & \multicolumn{6}{|c|}{ Service moisture content, $w_{3}, \%$} \\
\cline { 2 - 7 } & Moscow & St. Petersburg & Ekaterinburg & Novosibirsk & Vladivostok & Krasnodar \\
\hline Gas concrete D400 & 3,18 & 3,13 & 3,47 & 3,56 & 2,93 & 2,18 \\
\hline Fiberglass & 0,79 & 0,87 & 0,80 & 1,11 & 0,53 & 0,75 \\
\hline Polystyrene foam & 2,59 & 2,62 & 3,58 & 4,49 & 2,30 & 1,82 \\
\hline $\begin{array}{l}\text { Extruded polystyrene } \\
\text { foam }\end{array}$ & 0,32 & 0,35 & 0,24 & 0,28 & 0,23 & 0,38 \\
\hline
\end{tabular}

\section{Conclusion}

The results obtained in this study allow calculation for unsteady humidity regime of envelope structures containing autoclave cellular composite. The presented of calculation are of interest and can be used for calculation effective heat conductivity gas concrete walling [22, 23], as well as parameters of energy efficiency for heat insulating materials [10]. 


\section{Acknowledgments}

The research work is accomplished in framework of State Assignment № 14.2406.2014/K.

\section{Reference}

[1]. P.P.Pastushkov, K.I. Lushin, N.V. Pavlenko Absence of problem of condensate formation at internal surface of wall with bonded heat insulation, J. House construction. 6 (2014) 42-44.

[2]. Aksoezen M., Daniel M., Hassler U., KohlerI N. Building age as an indicator for energy consumption, J. Energy and Buildings. 87 (2015) 74-86.

[3]. Mamontov A.A., Jartcev V.P., Strulev S.A., Analysis of humidity of different insulators in envelope constructions during heating period service, J. Academia. Architecture and construction. 4 (2013) 117-119.

[4]. Jelle B. P. Traditional, state-of-the-art and future thermal building insulation materials and solutions - Properties, requirements and possibilities, J. Energy and Buildings. 43 (2011) 25492563.

[5]. G.I. Greenfeld, P.D. Kuptaraeva, Walling with autoclave gas concrete having outside insulation. Features of humidity regime at initial service period, J. Engineering and technical Journal. 8 (2011) 41-50.

[6]. E.M. Chernyishov, G.S. Slavcheva, Humidity conditions and behavior of engineering properties in construction materials when service, J. Academia. Architecture and Construction. 4 (2007) 70-77. [7]. M.S. Homoud, Performance characteristics and practical applications of common building thermal insulation materials, J. Building and Environment. 40 (2005) 353-366.

[8]. P.P. Pastushkov, Calculated and experimental study of cooling of envelope construction after heating cut, Bulletin of Moscow State University of Civil Engineering. 7 (2011) 312-318.

[9]. V.G. Gagarin, V.V. Kozlov, About of requirement to thermal protection and energy efficiency in project according to update edit of the Construction Regulation Standards «Building heat insulation», Bulletin of Moscow State University of Civil Engineering. 7 (2011) 59-66.

[10]. B.G. Gagarin, P.P. Pastushkov, Quantitative estimation of energy efficiency of energy saving affairs, J. Construction materials. 6 (2013) 7-9.

[11]. Construction rules 50.13330.2012. Updated edit of the Construction Regulation Standards 2302-2003 «Buildings Heat Insulation».

[12]. A.G. Perehozhentcev, I.Y. Gruzdo, Study of moisture diffusion in porous construction materials, Bulletin of Volgograd State Architectural and Constructional University. Issue: Construction and Architecture. 35(54) (2014) 116-120.

[13]. S.V. Kornienko, Temperature-humidity regime and heat insulating properties of envelope constructions with rim zones, Bulletin of Volgograd State Architectural and Constructional University. Issue: Construction and Architecture. 35(54) (2014) 62-69.

[14]. B.G. Gagarin, V.V. Kozlov, Mathematical model and engineering method of calculation of humidity conditions of envelope constructions, J. Academia. Architecture and Construction. 2 (2006) $60-63$.

[15]. V.N. Levchenko, G.I. Greenfield, Autoclave gas concrete production in Russia: prospective of subindustry development, J. Construction materials. 9(2011) 44-47.

[16]. G.I. Greenfield, S.A. Morozov, I.A. Sogomonyan, P.S. Zyiryanov, Humidity conditions of update constructions based on autoclave gas concrete when service period, J. Constructionengineering Journal. 2 (2011) 33-38.

[17]. A.S. Semchenkov, T.A. Ukhova, G.P. Sakharov About of correction of balanced humidity and heat conductivity of cellular concrete, J. Construction materials. 6 (2006) 3-7.

[18]. T. Schoch, O. Kreft, The influence of moisture on the thermal conductivity of AAC, $5^{\text {th }}$ International conference on Autoclaved Aerated Concrete «Securing a sustainable future»: Bydgoszcz, Poland, September, 14-17 (2011) 361-370.

[19]. V.V. Babkov, D.V. Kuznetsov, A.M. Gaisin, O.A. Rezvov, N.S. Samopheev, E.V. Morozova, Problem of service reliability of external wall of construction on the base of autoclave gas concrete 
blocks as well as opportunities of its moisture protection, J. Construction-engineering Journal. 8 (18) (2010) 28-31.

[20]. Vasilyev B.F. Ambient studies of temperature-humidity regime of apartment building, Moscow, State edition on construction and architecture, 1957.

[21]. Manual on calculation of humidity regime of envelope construction, Moscow, Stroyizdat, 1984.

[22]. G.S. Slavcheva, E.M. Chernyishov, D.N. Korotkih, Y.A. Kuhtin, Comparative service heat protecting characteristics of one- and two-layered wall gas concrete constructions, J. Construction materials. 4 (2007) 13-15.

[23]. A.I. Bedov, V.V. Babkov, A.I. Gabitov, A.M. Gaisin, O.A. Rezvov, D.V. Kuznetsov, E.A. Gafurova, D.A. Sinitsyin, Design arrangement and features of calculation of heat insulating of building outside wall based on autoclave gas concrete blocks, Bulletin of Moscow State University of Civil Engineering. 2 (2012) 98-103. 